\title{
Comparing Time Taken for Cannulating Internal Jugular Vein by USG Guided Approach: Short Axis versus Long Axis Technique
}

\author{
Shallu Chaudhary ${ }^{1}$, Ravikant Dogra ${ }^{2}$, Major Amit Atwal ${ }^{3}$ \\ ${ }^{1}$ Medical Officer (Anaesthesia), Health \& Family Welfare Department, Himachal Pradesh, India \\ ${ }^{2}$ Associate Professor, Department of Anesthesiology, IGMC Shimla Himachal Pradesh, India \\ ${ }^{3}$ Medical Officer, Military Hospital Jutogh Cantt, Shimla, Himachal Pradesh, India
}

Corresponding Author: Major Amit Atwal

\begin{abstract}
We have conducted our study in 80 patients admitted in the general ICU, requiring internal jugular vein cannulation. We formed 2 groups of 40 patients each that is:- Group 1 (short axis) and Group 2 (long axis). Under USG guidance, we cannulated the internal jugular vein with short axis view in group 1 and long axis view in group 2. Meanwhile the time taken to perform these cannulations was noted and then compared. After the study, we found that the internal jugular vein was cannulated much faster in short axis group as compared to the long axis group.
\end{abstract}

Keywords: Central venous cannulation, internal jugular vein, USG guided approach, short axis versus long axis technique

\section{INTRODUCTION}

Central venous cannulation in critically ill patients is preferably done under USG guidance ${ }^{1}$. Earlier blind landmark techniques were used but they are challenging to perform in difficult situations. USG however allows successful cannulation in a shorter average time ${ }^{2}$. USG provides real time imaging that is the needle can be visualized while entering the vein. There are various scanning axis available with USG like short axis, long axis, oblique views. In our study, we have compared short axis and long axis view. These two views have their own advantages and disadvantages. With short axis view, the vessel is seen in cross-section during cannulation. While in long axis view, the whole length of the vessel is viewed during cannulation.

\section{MATERIAL AND METHODS}

Our study was carried out in 80 patients that were admitted in the general ICU. All these patients required central venous access for their treatment. They were divided into two groups based on random allocation number table. Group1included short axis view and Group 2included long axis view. In each group there were 40 patients. Before starting the procedure, fresh informed consent was obtained from the patient's attendant. Adequate sedation and analgesia was given to the patient. The baseline vitals were recorded. Taking all aseptic precautions, the right internal jugular vein was cannulated under USG guidance with either of the two views as per the group of the patient. During the cannulation procedure, an observer recorded the following:-

- Time 1: Time taken from keeping ultrasound probe on the neck to first needle insertion.

- Time 2: Time from first needle insertion to ultrasound confirmation of presence of guide wire within the vein.

- Total time taken : Time $1+$ Time 2 


\section{OBSERVATION AND RESULTS Intergroup comparison of Time 1 (T1):- \\ In group $\mathrm{A}$, mean $\mathrm{T} 1$ was} $32.35 \pm 6.47$ seconds and in group $\mathrm{B}$, mean $\mathrm{T} 1$ was $46.50 \pm 16.57$ seconds ( $\mathrm{p}$ value 0.029). This was found to be statistically significant. Thus the time taken from keeping USG probe on neck to first needle insertion was found to be less in group A compared to group B.

Intergroup comparison of Time 2 (T2):-

In group $\mathrm{A}$, mean $\mathrm{T} 2$ was $136.95 \pm 18.91$ seconds and in group $\mathrm{B}$, mean $\mathrm{T} 2$ was $256.05 \pm 55.37$ seconds ( $\mathrm{p}$ value $0.001)$ which was found to be statistically significant. Thus the time taken from first needle insertion to USG confirmation of guide wire within the vein was found to be less in group A compared to group B.

Intergroup comparison of Total Time taken (T1+T2):-

In group $\mathrm{A}$, mean total time taken for guide wire insertion was $169.30 \pm 18.71$ seconds and in group B mean total time taken was $302.55 \pm 66.07$ seconds ( $\mathrm{p}$ value 0.004 ) which was statistically significant.

Thus the total time taken for guide wire insertion was less in group A compared to group B.

\section{INTERGROUP COMPARISON OF TIME1, TIME 2, AND TOTAL TIME TAKEN FOR CANNULATION}

\begin{tabular}{|l|c|c|c|c|c|}
\hline & GROU P & N & Mean & SD & P value \\
\hline \multirow{2}{*}{ TIME 1 } & $\mathrm{A}$ & 40 & 32.35 & 6.47 & \\
\cline { 2 - 6 } & $\mathrm{B}$ & 40 & 46.50 & 16.57 & 0.029 \\
\hline \multirow{2}{*}{ TIME 2 } & $\mathrm{A}$ & 40 & 136.95 & 18.91 & 0.001 \\
\cline { 2 - 5 } & $\mathrm{B}$ & 40 & 256.05 & 55.37 & \\
\hline \multirow{2}{*}{ TIME 1+TIME 2 (total time) } & $\mathrm{A}$ & 40 & 169.30 & 18.71 & \multirow{2}{*}{0.004} \\
\cline { 2 - 5 } & $\mathrm{B}$ & 40 & 302.55 & 66.07 & \\
\hline
\end{tabular}

\section{DISCUSSION}

Internal jugular vein cannulation can be done by the use of real time USG. Either of the two approaches can be undertaken. Short axis view is also known as out of plane view and Long axis view is also known as in plain view. Both the approaches have their own advantages and disadvantages.

With short axis approach, both the artery and vein are simultaneously viewed. There are less chances of arterial puncture. However during cannulation, the needle is not visible as it is advanced out of the scanning plane. While with long axis approach, we can visualize the entire length of the needle as it punctures the vessel. But the information of the carotid artery relative to the IJV may be lost during cannulation. Thus correct identification of the vessel, whether it is an artery or vein is important ${ }^{3}$.

In our study, we found that IJV cannulation was obtained much faster with short axis view approach as compared to the long axis view. However in a study conducted by $\mathrm{S}$. Shreshta et $\mathrm{al}^{4}$, short axis approach was compared with long axis approach and it was found that there was statistically no significant difference in between the two groups in terms of time required for cannulation.

Tammam et $\mathrm{al}^{5}$ conducted a similar study and suggested that the short axis and long axis approaches were comparable for IJV cannulation in critical care and hemodialysis patients. However Blaivas et $\mathrm{al}^{6}$ in his study concluded that the ultrasound users obtained vascular access faster with short axis approach as compared to long axis.

Real time USG guidance improves the success rate associated with IJV cannulation and should always be considered while cannulating patients ${ }^{7}$. Our study however had several limitations. We had taken only a limited number of patients and this study was performed over a limited period of time. Also the procedure was performed by $2^{\text {nd }}$ and $3^{\text {rd }}$ year anaesthesia residents under the supervision of consultants. Had the cannulation been done by the consultants themselves, the results 
might have been different. We did not include any difficulty scale for cannulation in our study.

\section{CONCLUSION}

We were able to cannulate all the patients in our study. Both the techniques:short axis view and long axis view have their own advantages and disadvantages. In our study, we conclude that these two techniques are comparable to each other in terms of time required to achieve cannulation.

Acknowledgement: None

Conflict of Interest: None

Source of Funding: None

\section{Ethical Approval: Approved}

\section{REFERENCES}

1. Vincent JL, Bihari DJ, Suter PM, et al. The prevalence of nosocomial infection in intensive care units in Europe. Results of the European prevalence of Infection in Intensive Care study. EPIC international advisory committee. JAMA 1995;274:63944.

2. Hrics P, Wilber S, Bland MP, Gallo. Ultrasound assisted internal jugular vein catheterisation in the ED. Am J Emerg Med 1998;16:401-3.
3. Chittoodan S, Breen D, O'Donnell BD, Iohom G. Long versus short axis ultrasound guided approach for internal jugular vein cannulation: A prospective randomised controlled trial. Med Ultrason 2011:13:21-5.

4. Shrestha GS, Gurung A, Koirala S. Comparison between long and short term technique for ultrasound guided cannulation of internal jugular vein. Ann Card Anaesth 2016;19:288-92.

5. Tammam TF, El-Shafey EM, Tammam HF. Ultrasound guided internal jugular vein access: Comparison between Short Axis and Long Axis Techniques. Saudi J Kidney Dis Transpl 2013;24(4):707-713.

6. Blaivas M, Brannam L, Fernandez E, Short axis versus Long axis approaches for teaching ultrasound guided vascular access on a new inanimate model 2003;10(12): 1307-11.

7. Palepu GB, Deven J, Subrahmanyam M, Mohan S. Impact of ultrasonography on central venous catheter insertion in intensive care. Indian J Radiol Imaging 2009;19:1918.

How to cite this article: Chaudhary S, Dogra R, Atwal MA. Comparing time taken for cannulating internal jugular vein by USG guided approach: short axis versus long axis technique. International Journal of Science \& Healthcare Research. 2021; 6(3): 251-253. DOI: https:// doi.org/10.52403/ijshr.20210743 